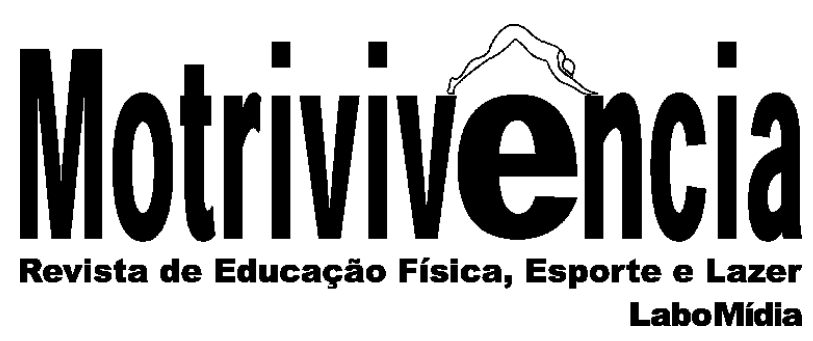

\title{
Um ensaio sobre o método emancipatório de ensino na Educação Física
}

RESUMO
Trata-se de uma reflexão sobre o método de emancipação intelectual
exposto por Jacques Rancière e suas possíveis contribuições para a
Educação Física no ensino superior. Percebemos que os métodos
empregados em uma disciplina do curso assemelham-se ao método
de embrutecimento, que segundo o autor, não contribuem para a
formação crítica dos alunos enquanto constituintes de uma sociedade
democrática.

PALAVRAS-CHAVE: Educação física; Metodologia de ensino; Jacques Rancière
Rafael Marques Garcia Mestre em Educação Física Universidade Federal do Rio de Janeiro, Departamento de Jogos, Rio de Janeiro, Brasil Rafa.mgarcia@hotmail.com D.http://orcid.org/0000-0002-0837-1493

Erik Giuseppe Barbosa Pereira Doutor em Ciências do Exercício e Esporte Universidade Federal do Rio de Janeiro, Departamento de Jogos, Rio de Janeiro, Brasil egiuseppe@eefd.ufrj.br [D. http://orcid.org/0000-0001-8129-4378 


\title{
Reflection about the emancipatory method of teaching in Physical Education
}

\begin{abstract}
It is a reflection about the method of intellectual emancipation exposed by Jacques Rancière and it's possible contributions to Physical Education in higher education. We perceive that the methods used in a discipline of the course resemble the method of brutalization, which according to the author, do not contribute to the critical formation of students as constituents of a democratic society.
\end{abstract}

KEYWORDS: Physical education; Teaching methodology; Jacques Rancière

\section{Reflexión sobre el método de enseñanza emancipatorio en Educación Física}

\section{RESUMEN}

Se trata de una reflexión sobre el método de emancipación intelectual expuesto por Jacques Rancière y sus posibles contribuciones a la Educación Física en la enseñanza superior. Se percibe que los métodos empleados en una disciplina del curso se asemejan al método de embrutecimiento, que según el autor, no contribuyen para la formación crítica de los alumnos como constituyentes de una sociedad democrática.

PALABRAS-CLAVE: Educación física; Metodología de la enseñanza; Jacques Rancière 


\section{PRECEITOS INICIAIS}

Existem diversos modelos de ensino que são adotados pelos/as professores/as universitários durante o processo de ensino-aprendizagem dos/as alunos/as em seu período de formação. Ao longo da história, percebe-se que o ambiente escolar implica diferentes concepções de humanidade e sociedade, ditando assim uma maneira para transmissão de valores e o conhecimento propriamente dito. Na Universidade Federal do Rio de Janeiro (UFRJ), encontramos pelos seus polos e núcleos diferentes métodos aplicados por docentes para transmissão desses substanciais.

Segundo Libâneo (2012) as diversas tendências pedagógicas podem ser divididas em dois grandes grupos: liberais e progressistas. Em cada um, encontramos diferentes técnicas: no primeiro, temos sua subdivisão em tradicional, renovada-progressivista, renovada não diretiva e tecnicista, já no segundo temos a libertadora, libertária e a crítico-social dos conteúdos. Para um melhor entendimento, realizar-se-á uma breve explicação sobre cada uma delas.

Ainda conforme Libâneo, o grupo de tendências liberais afirma que a escola tem por papel principal preparar os alunos para desempenhar seus respectivos papéis na sociedade, logo, todos devem se adaptar a valores e normas sociais conforme a cultura local. A técnica tradicional educa o aluno para que ele atinja uma plena realização através de seu próprio esforço. Admite-se que o professor detém todo o conhecimento e o aluno se apresenta ignorante, devendo este buscar sair deste estado através da cópia, memorização e repetição dos ensinamentos aprendidos (LUCKESI, 2011).

$\mathrm{Na}$ técnica renovada-progressivista, a cultura se acentua como desenvolvimento das aptidões individuais, assim, o aluno passa a ter um papel mais ativo em seu processo de aprendizagem através da valorização de suas tentativas - pesquisar, descobrir, realizar experimentos, entre outros. Assim, o processo de aprendizagem se daria através de um processo de autoaprendizagem onde o aluno buscaria através do meio, incorporar novos ensinamentos (LIBÂNEO, op.cit.).

$\mathrm{Na}$ técnica renovada não diretiva, a interação social se torna primordial no processo de aprendizagem. Logo, os esforços se voltam para adequar o pessoal às solicitações do ambiente coletivo. Através da percepção individual, cada aluno absorve e apresenta uma resposta diferente aos estímulos, processo este em que o professor se apresenta apenas como um facilitador (idem).

Por último, neste grupo, temos a técnica voltada para o tecnicismo, onde o professor se apresenta como um "reprodutor" de ensinamentos necessários para uma função específica social, ou seja, favorece o aperfeiçoamento da ordem social vigente atrelado ao sistema produtivo, onde se prioriza a formação de indivíduos capazes a atender às demandas de mercado. Assim, essa técnica 
veria o aluno como um ser passivo que depositaria em sua mente todo conhecimento aprendido através de associações (MATUI, 1998).

O segundo grupo, denominado progressista, prioriza uma análise crítica das realidades sociais, instigando os alunos a uma concepção crítica, ou seja, questionadora acerca das realidades vividas (LIBÂNEO, 2012). A técnica libertadora se assemelha à libertária ao defender a ideia de que o professor não deve pregar o autoritarismo, mas sim favorecer um processo de reflexão crítica. Paulo Freire (2011) diz que o ato de conhecimento na esfera educativa parte do princípio de reconhecimento por parte do aluno de que existem diversas estruturas para se buscar o conhecimento e ele é livre para elaborar e ordenar seus próprios conceitos apropriando-se dessas diversas maneiras que não lhe são apresentadas. Ao se tomar consciência deste aspecto, o aluno liberta sua consciência crítica e constrói ideais que o tornam capazes de pensar por si só sem ser manipulado pela política, sistema vigente, entre outros.

A técnica libertária, porém, acrescenta que somente o vivido pelo educando é memorizado e passa a ser utilizado, logo a vivência de tais situações é fundamental para sua assimilação. Ao se oferecer novos meios de aprendizagem que fogem da repressão imposta pelo sistema "professor sabe tudo e aluno não sabe nada”, o pensamento crítico é favorecido e contribui para a formação de não apenas alunos, mas cidadãos pensantes por si só (LIBÂNEO, op.cit.).

Por fim, a técnica crítico-social dos conteúdos vem com a finalidade de preparar o aluno para a vida adulta e suas controvérsias, fornecendo-lhe as capacidades básicas para exercer seu livre arbítrio conforme a ordem social e demais organizações da estrutura democrática, onde o desenvolvimento da aprendizagem ocorre através de sínteses de superação de visões nebulosas para unificadoras (idem).

Aliado às tendências acima, diversos pensadores e filósofos se debruçam sobre essas concepções e apresentam complementos às técnicas visando a formulação de uma corrente intelectual considerada a ideal. Um deles é Jacques Rancière (1940-atual), natural de Argélia (1940), é doutor em Filosofia (1980) e professor emérito de Estética e Política da Universidade de Paris VIII (Departamento de Filosofia), onde lecionou entre 1969 e 2000, e foi diretor do Programa do Collège International de Philosophie (Paris).

O autor inclina-se a delinear uma filosofia contemporânea da emancipação de forma polêmica. Para Galende (2012), sua radicalidade, no entanto, torna-o relevante frente à filosofia política, pois rejeita as noções de política como administração governamental do poder e entendida como transformadora dos oprimidos por um grupo de superiores que, para Rancière, encontram-se esgotadas no pensamento ocidental. 
Buscando romper com essa política hierarquicamente desigual, autoritária e opressora às identidades subalternas, em uma de suas obras, $O$ Mestre Ignorante, apresenta cinco lições sobre emancipação intelectual, abrangendo conceitos semelhantes aos de algumas técnicas e linhas de atuação supracitadas. As mensagens e ícones que daí depreendem nos inclinam para determinada metodologia de atuação que, em meio a um vasto repertório de métodos de ensino, apresenta-se como mais uma possibilidade de intervenção docente. A proposta de Rancière, neste contexto, é mais uma forma de problematizar novos modelos de ensino-aprendizagem na contemporaneidade com o intuito de promover a emancipação intelectual discente. Cabe frisar que não estamos aqui considerando esta abordagem como única referência válida, legítima ou universal, mas sim como uma proposta de reflexão para dialogar com os outros modelos de abordagem.

Nesta obra, Rancière trata sobre o conceito da emancipação intelectual. A narrativa se desenrola majoritariamente sobre as experiências vivenciadas pelo professor Jacotot, considerado o criador do método de emancipação intelectual. Sua descoberta provém a partir de uma experiência inusitada, onde fora convidado a ministrar aulas a alunos que apenas falavam o holandês, língua esta desconhecida pelo professor. Através de um intérprete, Jacotot orientou seus alunos a realizarem um estudo da língua francesa e, mesmo sem oferecer nenhuma explicação ou suporte, obteve resultados tão expressivos que colocaram em dúvida o papel do professor enquanto explicador: seria mesmo necessária a sua presença? Afinal, os alunos acabavam de lhe provar que não necessitaram de nenhuma intervenção do professor para apreender - sim, apreender, ou seja, assimilar o conteúdo, entender e reproduzir os ensinamentos adquiridos. Esse é o princípio da emancipação, onde o professor instiga o aluno a pensar e a desenvolver o seu próprio método de aprendizagem, sendo seu principal objetivo elevar os alunos "[...] gradativamente à sua própria ciência. [...] Ensinar era, em um mesmo movimento, transmitir conhecimentos e formar os espíritos, levando-os segundo uma progressão ordenada, do simples ao complexo" (RANCIÈRE, 2015, p. 19).

Assim, torna-se possível ensinar qualquer conteúdo, mesmo que o professor desconheça o assunto $^{1}$. O bom mestre sabe ensinar o que ignora através deste método emancipatório, ou seja, faz com que o aluno use sua própria inteligência para aprender, estimulando-o a desenvolver o seu próprio método de compreensão. A este processo se dá a nomenclatura de Ensino Universal, onde é possível aprender qualquer conteúdo.

\footnotetext{
${ }^{1}$ Sob esta concepção, não podemos confundir a proposta de discussão defendida por Rancière. A princípio, essa afirmação soa como desvalorização da formação docente, bem como a não necessidade do planejamento, pois estes atrapalhariam o processo de aprendizagem do estudante. No entanto, a real mensagem daí veiculada refere-se ao potencial do educador de, através da arte da distância, demonstrar-se ignorante do assunto para estimular no aluno a própria busca e o interesse de desvendar o misterioso, o mítico, o não conhecido.
} 
O emancipador não se preocupa com o que emancipado deve aprender, porque qualquer resultado apresentado por si só já é prova de um conhecimento adquirido. Assim, esta concepção contrapõe-se ao método tradicional aqui identificado como embrutecedor - que se dá através das explicações -, uma vez que neste último o mestre se distancia demasiadamente do aluno ao transmitir-lhe conteúdos fragmentados, período por período, sempre mostrando que existe um degrau de conhecimento separando-o do discente, fazendo dele um eterno refém da presença de um explicador.

A necessidade de explicações, presente em todos os sistemas de ensino, oferece uma visão subjetiva dos assuntos. Por mais que o explicador esteja fazendo uso de dados objetivos, estará subjetivando-os conforme seu entendimento, logo, qual seria a finalidade de um professor para explicar o conteúdo de um livro, se o próprio aluno também fará sua interpretação do exposto pelas páginas? Esse raciocínio nos leva a crer que um pai ignorante poderia substituir facilmente um mestre explicador, porém falta-lhe a arte da distância (idem) referente ao distanciamento entre o que foi ensinado e o sujeito instruído em conformidade com o seu tempo de apreensão. O que se caracteriza neste processo de explicação é a ideia de que o mestre sempre se encontrará em patamar superior ao aluno. Ele seria o detentor do conhecimento e o aluno o ignorante que necessita de outro mais inteligente para educá-lo, sendo instigado para evidenciar se realmente apreendeu algo. Eis aqui melhor definido o princípio do embrutecimento. O mestre embrutecedor é aquele que através de seus métodos faz com que o aluno aprenda e, para tanto, está constantemente pesquisando novas técnicas, metodologias e ferramentas para melhor transmitir o conteúdo e checar se realmente houve a aprendizagem. Através destes implementos, o mestre perceberá quando seu aluno apresentar dificuldades de entendimento, apresentando-lhe uma nova explicação e estimulando sua inteligência conforme as orientações transmitidas - que podem vir a transformá-lo num futuro explicador (ibidem).

Tais concepções fornecem estruturas para estabelecer patamares de igualdade e desigualdade dos saberes. A igualdade tornou-se o objetivo a ser conquistado. Parte-se, para isto, de um pressuposto de que todos se encontram desiguais em inteligência por se mostrarem ignorantes em determinados campos. "Não há espírito superior que não encontre um mais superior ainda, para rebaixá-lo; não há espírito inferior que não encontre outro mais inferior ainda, para desprezar" (RANCIÈRE, 2015, p. 66).

A instituição educacional tal qual a conhecemos - embrutecedora -, vem, portanto, para favorecer a equidade intelectual em conformidade com os ideais do progressivismo, entretanto, fazse "prisioneira do paradigma pedagógico que reconstitui indefinidamente a desigualdade que pretende suprimir" (op.cit., p. 14) uma vez que reforça justamente o próprio embrutecimento, ou 
seja, confirma a existência de dois patamares, o do professor, sábio, e o do aluno, ignorante, assim como o constatado nas velhas filosofias, e que sempre estabelecerá uma desigualdade. Para se atingir a igualdade, todos deveriam chegar ao mesmo degrau, o que exige muito tempo e não é alcançado pelas escolas em geral.

Já na emancipação de Jacotot, a igualdade não está no saber equivalente, bem ou mal, pouco ou muito, mas sim na capacidade dos saberes: cada um carrega consigo um conhecimento e um determinado interesse em aprender respectivos assuntos. A única desigualdade seria o quão forte é a vontade dos envolvidos neste processo, marcando a dualidade dessas concepções. Não existe hierarquia da capacidade intelectual.

Um elemento que vem a interferir diretamente neste processo é a vontade do aluno em aprender. Qualquer indivíduo pode vir a absorver determinado conteúdo na ausência de um explicar. É assim conosco dia-a-dia: através de nossos anseios, buscamos por respostas de assuntos que nos interessam e nos afastamos de temas que não nos chamam a atenção. Por vezes acredita-se em uma diferença hierárquica da capacidade intelectual das pessoas, principalmente pela desigualdade de condições, porém o que realmente existe nessas esferas é uma diferença nas manifestações da inteligência (RANCIÈRE, 2015).

Sendo assim, o Ensino Universal se apresenta de forma prazerosa. A partir de um conhecimento básico sobre qualquer aspecto, o aluno pode-se valer desta singela sabedoria para relacionar todo o restante. Eis o verdadeiro conhecimento, a verdadeira maneira de se estimular a busca e absorção dos saberes. Rancière nos revela o quão glorioso esse método é, em comparação com a dura rotina viciosa da decoração imposta pelos métodos embrutecedores: através da constante repetição, cultiva-se apenas a memória, enquanto que a universalidade contempla a "[...] a inteligência, o gosto e a imaginação. Vossas crianças decoram. Este é vosso primeiro erro. E eis o segundo: vossas crianças não aprendem de cor” (idem, p. 45).

Podemos notar, portanto, o quão deficitário se torna uma instituição de ensino ao valer-se apenas de métodos tradicionais para transmitir os mesmos conteúdos a todos os alunos e esperar os mesmos resultados para aprovação, conforme a afirmação de Catani (2007): para a autora, a escola agrava as desigualdades oriundas das posições sociais, onde se privilegia a cultura dominante daquele que melhor responde a uma metodologia.

A solução seria, portanto, valer-se do Método Universal apenas com mestres ignorantes? Talvez. "Ensinar o que se ignora é simplesmente questionar sobre tudo o que se ignora" (RANCIÈRE, op.cit., p. 53), entretanto um mestre emancipador não necessita desconhecer do assunto para emancipar. Ele pode sim dominar determinado saber, porém neste processo se valeria de interrogações para instigar o pensamento dos alunos, atentando-se ao fato de que, por saber as 
respostas, não deveria induzi-las tão facilmente. Para confirmar que seu método está funcionando, ele verificaria se seus alunos apresentam resultados contínuos, ou seja, buscam informações novas e acrescentam aos conteúdos já conhecidos (idem). Qualquer resultado que venha a ser apresentado já é uma conquista, todos os emancipados são capazes de apreender.

O que se busca evitar neste intenso processo de construção de conhecimento é o propagado pelo senso comum, onde as opiniões se perpetuam de forma errônea carregando estruturas ultrapassadas. O poder crítico do aluno parte do exercitar promovido pela sua emancipação, da sua ânsia de procurar respostas para aquilo que não conhece e, através desta postura, o torna capaz de criticar, pensar e repensar qualquer ensinamento que a ele se apresente. É um processo contínuo por toda a vida regido através das especificidades individuais de cada discente, trazendo novamente à tona a vontade em se lançar ao desconhecido.

A idiotização do indivíduo não se prende apenas ao campo escolar. Ela se estende para os campos sociais da democracia. Aquele que não questiona, não critica e não pensa por si só é facilmente corrompido com ideias falsas e bizarras proferidas por seres constituídos de palavras metafóricas e cheias de analogias - os políticos (ibidem). A razão ao homem atribuído é de suma importância: quando ele percebe o potencial que carrega, exerce a totalidade de seu poder próprio: não será mais ludibriado tão facilmente.

Por isso se faz tão importante a presença de escolas e universidades que se valham de métodos semelhantes ao Universal para instigar o criticismo e o pensar dos indivíduos em seu constante processo de formação. Deixá-lo à mercê da reprodução rotineira de ideais pautados em senso comum, que ocorre constantemente em ambiente familiar, é abstê-lo de um ensino crítico que o instigará a pensar por si só, a desenvolver seus pensamentos e conhecimentos fundamentados. Que as explicações aperfeiçoadas se sobressaiam às velhas explicações sustentadas de geração a geração (RANCIÉRE, 2015).

O Ensino Universal transpassa as barreiras escolares e auxilia no processo de construção de um cidadão crítico, bem instruído e capaz de pensar por si só, vindo a promover mudanças na composição da sociedade ao qual está inserido. Sendo assim, questiona-se: por que a sociedade não se molda aos caprichos de Jacotot? Simples, pelo fato de o ser humano mostrar-se incansável em sua necessidade de querer explicar o mundo e tudo à sua volta. A razão se mostra salvadora ao exercer o poder de igualdade entre os seres intelectuais (idem) e se estende para toda instituição, que busca através de orientações explicar a sociedade através de suas desigualdades.

Assim, o método emancipador se mostraria antitético justamente por afirmar que o ser humano não necessita de explicações, o que reforça ainda mais o embrutecimento através de técnicas tradicionais, onde não se faz necessário pensar, opinar ou estabelecer crenças sobre 
determinado conteúdo, entretanto, caso a sociedade fosse emancipada, ela “[...] repudiaria a divisão entre aqueles que sabem e aqueles que não sabem, entre os que possuem e os que não possuem a propriedade da inteligência" (ibidem, p. 104).

\section{A EXPERIÊNCIA}

Este ensaio foi inspirado na experiência em uma disciplina prática ${ }^{2}$ da Escola de Educação Física e Desportos da UFRJ. A vivência contou com 10 encontros de 3 horas cada, totalizando 30 horas/aula. A turma era composta de 20 alunos $^{3}$ sendo 11 homens e 9 mulheres, todos com relativa vivência na modalidade, uma vez que a disciplina era de livre-escolha e ministrada em dia e horário incomuns - aos sábados, de $8 \mathrm{hs}$ às $11 \mathrm{hs}$-, mas que favoreceram a inscrição desses atores. $\mathrm{O}$ professor da disciplina é especialista na modalidade, tendo um currículo invejável: atleta da modalidade durante a juventude, técnico da mesma em equipes universitárias e agora docente e pesquisador pela UFRJ desde 2009, o que lhe confere muita propriedade tanto prática quanto teórica para ministrar o curso.

O processo de experenciação se deu durante no período de 2015.2, ocasião em que o autor exerceu a função de aluno da disciplina e esteve presente em todas as aulas. O professor iniciou seus trabalhos em outubro de 2015 , em caráter experimental e de forma intensiva, ou seja, as aulas foram ministradas com carga horária de 3 horas de modo que até janeiro fosse encerrada.

É importante atentar-se, nesta reflexão, para a maneira como a Educação Física veio se constituindo enquanto área científico-acadêmica em terras brasileiras. Historicamente, principalmente no último século antes dos anos de 1980, a matriz predominante nesta área de conhecimento desempenhava papel fundamental para aptidão física e desenvolvimento dos esportes. Apresentava-se intimamente ligada e influenciada pelas instituições militares e as ciências naturais, priorizando dados de cunho biológico e seus semelhantes, o que ocasionou a ausência de discussões sobre reflexões pedagógicas (BRACHT, 1999).

A partir da entrada mais contundente das ciências sociais e humanas, iniciada na década de 1980, a Educação Física passou por um processo de problematizações metodológicas que frisavam a formação integral, ou seja, a construção de um caráter biopsicossocial, contrapondo-se ao paradigma da aptidão física e deflagrando o Movimento Renovador da Educação Física brasileira (COLETIVO DE AUTORES, 1992).

\footnotetext{
${ }^{2}$ A pedido do docente responsável, não identificaremos a disciplina, gravando-a apenas como V.P.

${ }^{3}$ Vale lembrar que os observados foram comunicados sobre a realização das tarefas do pesquisador e consentiram livremente em participar através de uma declaração de próprio punho.
} 
Nota-se, no entanto, uma forte resistência às mudanças pedagógicas neste campo em função de uma possível descaracterização da Educação Física, ainda muito fundamentada em traços biológicos. Em contrapartida, na atualidade é possível identificar vários modelos que possibilitam aos professores de Educação Física uma intervenção mais ampla e questionadora acerca dos saberes relacionados à área, tais como metodologia do ensino aberto, crítico superadora, construtivista e crítico emancipatória (OLIVEIRA, 1997). Para ilustrar esses modelos, organizamos um quadro descritivo de cada categoria com suas respectivas características:

Quadro 1- Métodos de ensino e suas características

\begin{tabular}{|c|c|c|c|c|c|}
\hline Métod & $\begin{array}{l}\text { Idealiz } \\
\text { adores }\end{array}$ & $\begin{array}{l}\text { Objeto } \\
\text { de estudo }\end{array}$ & $\begin{array}{l}\text { Objetivo( } \\
\text { s) }\end{array}$ & Conteúdo(s & Enfoqu \\
\hline $\begin{array}{l}\text { Ensino } \\
\text { aberto }\end{array}$ & $\begin{array}{l}\text { Reiner } \\
\text { Hildebrandt e } \\
\text { Ralf Laging }\end{array}$ & $\begin{array}{l}\text { Movime } \\
\text { nto e implicações } \\
\text { sociais }\end{array}$ & $\begin{array}{l}\text { Desenvol } \\
\text { ver o movimento, } \\
\text { sua amplitude e } \\
\text { complexidade com } \\
\text { a intenção de } \\
\text { proporcionar } \\
\text { autonomia em } \\
\text { ações pessoais }\end{array}$ & 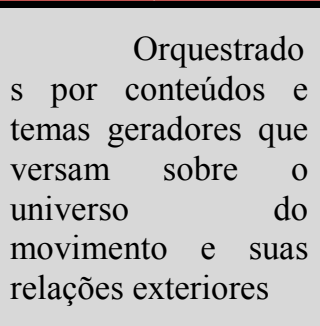 & $\begin{array}{l}\text { Particip } \\
\text { ação interativa } \\
\text { entre a intenção } \\
\text { do professor e os } \\
\text { objetivos de ação } \\
\text { dos alunos }\end{array}$ \\
\hline $\begin{array}{l}\text { Crítico } \\
\text { Superadora }\end{array}$ & $\begin{array}{l}\text { Coleti } \\
\text { vo de autores }\end{array}$ & \begin{tabular}{l}
\multicolumn{2}{c}{ Cultura } \\
corporal do \\
movimento e as \\
suas dimensões
\end{tabular} & $\begin{array}{lr} & \text { Apropriaç } \\
\text { ão da } & \text { cultura } \\
\text { corporal } & \text { enquanto } \\
\text { parte } & \text { constitutiva } \\
\text { da realidade social }\end{array}$ & $\begin{array}{l}\text { Multiplicida } \\
\text { de histórica da } \\
\text { cultura corporal, tais } \\
\text { como jogos, } \\
\text { ginásticas, danças e } \\
\text { esportes }\end{array}$ & $\begin{array}{l}\text { Interpret } \\
\text { ação das práticas } \\
\text { constitutivas da } \\
\text { cultura corporal } \\
\text { como práticas } \\
\text { sociais }\end{array}$ \\
\hline $\begin{array}{l}\text { Constr } \\
\text { utivista }\end{array}$ & $\begin{array}{r}\text { João } \\
\text { Batista Freire }\end{array}$ & $\begin{array}{l}\text { Motricid } \\
\text { ade humana }\end{array}$ & $\begin{array}{l}\text { Autocons } \\
\text { ciência corporal e } \\
\text { o reconhecimento } \\
\text { de suas expressões } \\
\text { no mundo }\end{array}$ & \begin{tabular}{ll}
\multicolumn{2}{c}{ Cultura, } \\
educação & da \\
motricidade, & dos \\
símbolos e dos \\
sentidos
\end{tabular} & \begin{tabular}{lr}
\multicolumn{2}{c}{ Desenvo } \\
lvimento da \\
consciência do \\
saber através da \\
metodologia do \\
conflito entre o \\
que se sabe e o \\
que precisa ser \\
aprendido
\end{tabular} \\
\hline $\begin{array}{r}\text { Crítico } \\
\text { emancipatório }\end{array}$ & Elenor & $\begin{array}{l}\text { Movime } \\
\text { nto humano, } \\
\text { esportes e suas } \\
\text { transformações } \\
\text { sociais }\end{array}$ & $\begin{array}{l}\text { Aplicar o } \\
\text { movimento } \\
\text { conscientemente e } \\
\text { de forma livre e } \\
\text { funcionalizada }\end{array}$ & $\begin{array}{l}\text { Movimento } \\
\text { humano através das } \\
\text { práticas corporais e } \\
\text { atividades lúdicas }\end{array}$ & $\begin{array}{l}\text { Estratég } \\
\text { ia didática na } \\
\text { tríade de ação } \\
\text { trabalho- } \\
\text { interação- } \\
\text { linguagem }\end{array}$ \\
\hline
\end{tabular}

Fonte: Os autores

A partir dos expostos e das constantes discussões envolvendo reflexões pedagógicas na Educação Física brasileira, podemos perceber formas culturais atuantes sobre o movimento humano que visam subverter as classificações hierárquicas pautadas nas ciências biológicas não para criar uma nova hierarquização, mas sim para equilibrar preceitos de ambas as áreas. A partir dessa reflexão, torna-se possível problematizar mecanismos socioculturais e pedagógicos do movimento humano, proporcionando debates e ponderações sobre os elementos vigentes onde a emancipação da Educação Física, nesta ótica, apresenta-se como contributo à formação consciente e crítica de 
sujeitos no que tange a tomada de decisões em múltiplas esferas, tais como a corporal, cultural e social, agregando-se na ideação de um cidadão mais politizado e crítico (COLETIVO DE AUTORES, 1992; BRACHT, 1999).

Ainda, conforme Bracht (1999, p. 81), “é preciso ter claro que a própria utilização de um novo referencial para entender o movimento humano está na dependência da mudança do imaginário social sobre o corpo e as atividades corporais". Nesta esfera, entender o movimento humano precisa transpassar tanto ciências biológicas quanto sociais, não renegando a importância de cada área, mas sim convergindo seus conceitos para alcançar uma unanimidade na discussão pedagógica deste campo científico (idem).

Após esta breve contextualização, apenas para uma compreensão imediata do assunto, adentraremos na sessão seguinte, referente ao tratamento dos dados. Para tanto, organizamos o bloco denominado "Aplicação Metodológica da Disciplina” com o intuito de registrar nossas análises e discussões.

\section{APLICAÇÃO METODOLÓGICA DA DISCIPLINA}

Para Bossle (2002), o planejamento de ensino é de fundamental importância e deve ser estruturado conforme os ensinamentos que serão transmitidos e de forma progressiva.

$\mathrm{Na}$ ementa da disciplina formulada e disponibilizada pelo professor encontram-se os aspectos que foram trabalhados ao longo do período: origem e evolução do V.P.; fundamentos das técnicas e táticas individuais e coletivas; noções das regras e o contexto sócio-histórico-cultural e; princípios didático/pedagógicos para o processo ensino/aprendizagem. Encontram-se também o objetivo geral - conhecer os métodos para o ensino dos fundamentos básicos do V.P., assim como noções de regras e planejamento para iniciação na modalidade - e os objetivos específicos: demonstrar conhecimentos teóricos e práticos para o ensino dos sistemas de jogo mais utilizados no V.P.; conhecer técnicas de aperfeiçoamento dos fundamentos de jogo, como atributo para aplicação em futura docência em diversos âmbitos de ensino; participar de estágios com equipes e na organização de competições do V.P.; aplicar uma bateria de testes físicos direcionados à modalidade e; elaborar um planejamento anual que vise desenvolver os fundamentos básicos do V.P.

O conteúdo programático da disciplina se desenvolveu conforme a seguinte ordem, utilizando-se de aulas expositivas e práticas: histórico do V.P. e sua evolução; habilidades básicas 
para a prática do desporto; regras do jogo; jogos pré-desportivos; fundamentos do V.P.; sistemas de jogo e; planejamento de aulas.

Notamos que o professor impôs normas e diretrizes a serem seguidas, como a assiduidade e pontualidade e o uniforme da EEFD, por exemplo. Transmite os ensinamentos de forma a fornecer um suporte básico para a realização de futuras avaliações. No primeiro teste de caráter teórico, realizado no dia 23/01/2016, formulou questões que exigiam respostas elaboradas sobre os ensinamentos passados, além de exigir entendimento das regras, histórico e demais fatores envolvendo o esporte. No segundo teste, dito prático, os alunos assistiram a uma partida de V.P., devendo identificar sistemas do jogo referentes aos fundamentos e às posições em quadra.

O processo didático-pedagógico se deu respeitando aos seguintes critérios: pelo fato de o professor ser especialista na modalidade, utilizou-se de métodos liberais semelhantes ao positivismo para transmitir o conhecimento (LIBÂNEO, 2012), enquadrando-se assim na técnica tradicional onde o docente possui postura ativa e é detentor do conhecimento, sendo o aluno um ser passivo, ignorante $^{4}$ e devendo repetir e decorar os elementos adquiridos (LUCKESI, 2011). Configurou-se, assim um processo de distanciamento entre docente e discente, regido conforme o domínio do conteúdo e que reforça o princípio da desigualdade embrutecedora (RANCIÈRE, 2015). Um exemplo desta inferência pode ser verificado no seguinte diálogo entre docente (D) e aluno (A) após a apresentação de uma aula por um grupo de discentes:

D: Como você avalia a aula?

A1: Foi boa...

D (com feição de impaciência): Então essa é sua contribuição para a turma? Várias pontuações a fazer e seu único comentário sobre uma aula de 50 minutos é esse? (expressão de deboche).

No entanto, ao longo do período, percebemos uma inconstância, uma vez que o docente mostrava-se ora fechado ao diálogo com a turma (exemplo 1: diálogo embrutecedor), ora aberto (exemplo 2: conduta emancipatória).

\section{Exemplo 1: Diálogo embrutecedor}

D: Não sei se vai dar tempo de aplicar todas as provas. O que vocês acham que podemos fazer?

A2: Olha professor, acho que podemos realizar algum trabalho ou substituir algumas avaliações.

A3: Concordo, poderíamos desenvolver outras formas de avaliação.

\footnotetext{
${ }^{4}$ Este termo encontra guarida em Rancière (2015), que o define, grosso modo, como um estado de desconhecimento sobre determinado assunto.
} 
$D$ (após alguns segundos refletindo em silêncio): Pensando bem, não vou mudar nada não, estava no cronograma e não é justo prejudicar quem já se programou. Vai ser isso mesmo!

\section{Exemplo 2: Conduta emancipatória}

Por estar ofertando a disciplina pela primeira vez e ter um grupo "cobaia", em decorrência de adversidades que se apresentaram como chuva, indisponibilidade de horário em determinados dias, entre outros, buscou meios alternativos para suprir as horas perdidas. Em conjunta formulação com a turma, chegaram a consensos: um deles foi transferir a aula de Copacabana para a Barra da Tijuca em um dia que o primeiro local se encontrava indisponível para aula. Esse acordo se deu de forma antecipada, não prejudicando nenhum dos alunos envolvidos.

A exemplificação dos dois exemplos traz à tona uma relação dual entre as condutas didáticas do professor, ou ainda, uma mescla entre os métodos abertos e acríticos ${ }^{6}$. Uma leitura que daí desponta refere-se à adoção, pelo docente, de novos modelos pedagógicos mais atuais na Educação Física, no entanto, talvez em função de um pensamento tradicional sobre a área, aqui identificado com viés de cunho biológico e tecnicista (BRACHT, 1999), o docente apresenta procedimentos que transitam entre as fronteiras de identificação e reconhecimento da Educação Física enquanto campo científico.

Em suas aulas teóricas, que ocorreram no campo da modalidade propriamente dito, o conteúdo foi exposto de forma oral. Abordaram-se temas pertinentes ao histórico do V.P. e a cada encontro, foi solicitado um resumo de um capítulo do livro de regras para posteriores discussões em grupo. Ao questionar os alunos sobre os temas abordados, caracterizou-se o processo de memorização oriundo da repetição, além de inclinar ligeiramente os discentes à resposta correta através de gestos específicos da modalidade.

Essa abordagem, conhecida na área da Educação Física como desenvolvimentista, é recorrente e se manifesta através da constante memorização e repetição do conhecimento de forma fragmentada, subentendendo-se que o conhecimento é internalizado via corpo. Neste processo, o papel do professor é restrito à reprodução de conhecimentos pré-estabelecidos cujo ensino objetiva transmitir normas, juízos, crenças e valores também já pré-determinados (OLIVEIRA, 2005), corroborando assim com a escola tradicional de ensino (SAVIANI, 2008).

\footnotetext{
${ }^{5}$ Termo utilizado pelo próprio professor para caracterizar a primeira turma da disciplina.

${ }^{6}$ Neste caso, tratamos como métodos abertos aqueles em que o foco principal encontra-se centrado na ação discente, enquanto os acríticos priorizam relações hierárquicas dos saberes.
} 
Quando tentava se distanciar do assunto, por ter muito domínio da disciplina, não conseguia se afastar completamente de modo a formular questões que instigassem um pensamento crítico dos alunos.

Fica explícita a visão de que os alunos são impossibilitados de aprender todo o conteúdo por si devido à complexidade do mesmo e necessitam da presença de um professor explicador, este fundamental para favorecer o processo de aprendizagem, assemelhando-se à técnica tradicional de ensino (LUCKESI, 2011; LIBÂNEO, 2012) e ao método de embrutecimento descrito por Rancière (2015).

Nas aulas práticas, que ocorreram sempre após o tempo teórico e também no espaço da modalidade, priorizou-se pela repetição de movimentos para fixar a correta execução da técnica de cada fundamento através de aulas caracterizadas como técnicas, vindo a conferir uma abordagem que priorizava pela aptidão física e aperfeiçoamento das habilidades da modalidade (COLETIVO DE AUTORES, 1992; BRACHT, 1999).

Não estamos neste trabalho almejando denunciar ou ainda condenar práticas docentes na formação de professores, mas sim refletir sobre as formas de conhecimento que se cruzam na construção dos sujeitos enquanto profissionais. Não se pode, nesta conjuntura, esquecer o contexto em que esses modelos foram e são desenvolvidos, ou seja, não é possível ignorar uma tradição que marca a forma como os docentes desenvolvem suas práticas e que está relacionada com a história da Educação Física e do Esporte. Sendo assim, é importante atentar-se para a forma como tais conceitos e valores permeiam-se ao longo dos anos, estabelecendo (in)verdades e saberes absolutos que culminam, por fim, na própria (re)construção de estimas das práticas pedagógicas.

\section{CONSIDERAÇÕES FINAIS}

Podemos perceber que o professor da disciplina V.P. apresentou, durante a realização deste ensaio, condutas próximas ao embrutecedor (RANCIÈRE, 2015) conforme a tendência liberal, tradicional (LIBÂNEO, 2012) e clássica da Educação Física (BRACHT, 1999).

Sua presença fazia-se necessária para ditar e passar o conteúdo, devendo os alunos copiar, memorizar e reproduzir os ensinamentos principalmente durante a realização de testes teóricos e práticos. A desigualdade promovida pelo sistema educacional tradicional se fez presente, ou seja, além de evidenciar-se um distanciamento demasiado de saberes entre o mestre e os alunos, este se perpetua inclusive entre os discentes, onde os alunos que sabem mais acerca dos aspectos abordados foram sempre selecionados para responder a perguntas ou simular situações de jogo. 
O aluno, caso não apresentasse um bom desempenho nos testes, teria sua capacidade reduzida, ou seja, suas demais valências não seriam consideradas, até mesmo por uma questão estrutural do sistema educacional que foge às análises aqui promovidas - afinal, a disciplina em questão é sobre V.P. De forma geral, os discentes não foram instigados em sua totalidade a pensar de forma crítica acerca do conteúdo transmitido, principalmente no que diz respeito às regras da modalidade: "Por ser regra, deve ser seguida e ponto final acabou!"”.

Foram aplicados instrumentos de avaliação que priorizavam a capacidade de memorização e reprodução fidedigna do transmitido em sala. Os resultados demonstrados pelos alunos nos testes corresponderam ao esperado, porém não comprovam se realmente apreenderam V.P. e seus aspectos.

Convém ressaltar aqui que a iniciativa deste ensaio é limitada a uma reflexão, não contemplando maiores aprofundamentos teórico-metodológicos no campo da Educação Física, que se apresenta amplo, vasto e extenso. Recomendamos a continuidade de estudos relacionados à temática, através de uma profunda imersão às obras de Rancière e suas possíveis contribuições para a Educação Física, vislumbrando novas possibilidades de construção do conhecimento mais horizontais.

\section{REFERÊNCIAS}

BOSSLE, Fabiano. Planejamento de ensino na educação física: Uma contribuição ao coletivo docente. Movimento, v. 8, n. 1, p. 31-39, 2002.

BRACHT, Valter. A constituição das teorias pedagógicas da educação física. Cadernos Cedes, v. 19, n. 48 , p. 69-88, 1999.

CATANI, Denice Bárbara. A educação como ela é. Revista Educação, São Paulo, vol. 5, Especial: Biblioteca do Professor, Bordieu pensa a Educação, p.16-25, set. 2007.

COLETIVO DE AUTORES. Metodologia do ensino da educação física. São Paulo: Cortez, 1992. FREIRE, Paulo. Pedagogia da autonomia: saberes necessários à prática educativa. $2^{\mathrm{a}}$ impressão da 43. ed. São Paulo, Paz e Terra, 2011.

GALENDE, Federico. Rancière: uma introduccion. Buenos Aires, Editorial Quadrata, 2012.

LIBÂNEO, Jose Carlos. Democratização da Escola Pública. 27. ed. São Paulo: Edições Loyola, 2012.

LUCKESI, Cipriano Carlos. Filosofia da educação. 2. ed. São Paulo: Cortez, 2011.

MATUI, Jiron. Construtivismo. São Paulo: Editora Moderna, 1998.

${ }^{7}$ Resposta do professor a uma pergunta do aluno H.C., que questionava o porquê da adoção de determinada medida para com um determinado jogador. 
OLIVEIRA, Amauri Aparecido Bassoli de. Metodologias emergentes no ensino da educação física. Revista da Educação Física/UEM, v. 8, n. 1, p. 21-27, 1997.

OLIVEIRA, Vitor Marinho. Consenso e conflito: Educação Física brasileira. Rio de Janeiro: Shape, 2005.

RANCIÈRE, Jacques. O mestre ignorante: cinco lições sobre a emancipação intelectual; tradução de Lilían do Valle - 3. ed. 4 reimp. - Belo Horizonte: Autêntica Editora, 2015.

SAVIANI, Demerval. Escola e Democracia. Campinas: SP, Autores Associados, 2008. 


\section{NOTAS DE AUTOR}

\section{LICENÇA DE USO}

Os autores cedem à Motrivivência - ISSN 2175-8042 os direitos exclusivos de primeira publicação, com o trabalho simultaneamente licenciado sob a Licença Creative Commons Attribution Non-Comercial ShareAlike (CC BY-NC SA) 4.0 International. Estra licença permite que terceiros remixem, adaptem e criem a partir do trabalho publicado, desde que para fins não comerciais, atribuindo o devido crédito de autoria e publicação inicial neste periódico desde que adotem a mesma licença, compartilhar igual. Os autores têm autorização para assumir contratos adicionais separadamente, para distribuição não exclusiva da versão do trabalho publicada neste periódico (ex.: publicar em repositório institucional, em site pessoal, publicar uma tradução, ou como capítulo de livro), com reconhecimento de autoria e publicação inicial neste periódico, desde que para fins não comerciais e compartilhar com a mesma licença.

\section{PUBLISHER}

Universidade Federal de Santa Catarina. Programa de Pós-Graduação em Educação Física. LaboMídia - Laboratório e Observatório da Mídia Esportiva. Publicado no $\underline{\text { Portal de Periódicos }}$ UFSC. As ideias expressadas neste artigo são de responsabilidade de seus autores, não representando, necessariamente, a opinião dos editores ou da universidade.

\section{EDITORES}

Mauricio Roberto da Silva, Giovani de Lorenzi Pires, Rogério Santos Pereira.

\section{HISTÓRICO}

Recebido em: Outubro/2017

Aprovado em: Novembro/2017 